\title{
Detecting hydrogen using TiO2-B2O3 at different operating temperature
}

\begin{abstract}
Performance of TiO2-B2O3 gas sensor that annealed using nitrogen at $650^{\circ} \mathrm{C}$ for 30 minutes was observed and analyzed. The sensing film of the gas sensor was prepared by mixing $\mathrm{TiO} 2-\mathrm{B} 2 \mathrm{O} 3$ with an organic binder. The sensing film was characterized by field emission scanning electron microscopy (FESEM) and X-ray diffraction (XRD). The gas sensor was exposed to hydrogen at a concentration of $100-1000 \mathrm{ppm}$ with operating temperatures of $100^{\circ} \mathrm{C}$ and $200^{\circ} \mathrm{C}$. However, no response was detected for $100 \mathrm{ppm}$ at $100^{\circ} \mathrm{C}$. But, as the operating temperature was increased to $200^{\circ} \mathrm{C}$, the gas sensor indicated a good response for $100 \mathrm{ppm}$ of hydrogen. The gas sensor exhibited p-type response based on decreased current when exposed to hydrogen. The sensitivity of gas sensor was calculated at 1.00, 2.18 and 3.58 for $100 \mathrm{ppm}, 500 \mathrm{ppm}$ and $1000 \mathrm{ppm}$ respectively, at an operating temperature of $200^{\circ} \mathrm{C}$
\end{abstract}

Keyword: Gas sensor; TiO2-B2O3; Hydrogen; Nitrogen; Organic binder 